\title{
CONTRIBUTION OF CONFORMAL ANTENNAS TOWARDS SUSTAINABLE AIRCRAFT
}

\author{
P. VRCHOTA* ${ }^{*}$ A. PRACHA $\check{R}^{\dagger}$, M. ŠMÍD ${ }^{\ddagger}$ AND J. MIDDEL ${ }^{\S}$ \\ ${ }^{*}$ Czech Aerospace Research Centre (VZLU) \\ Beranovych 130, 19905 Prague, Czech Republic \\ e-mail: vrchota@vzlu.cz,web page: http://www.vzlu.cz

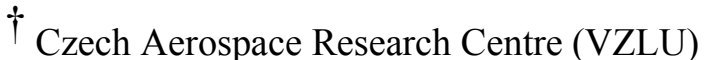 \\ Beranovych 130, 19905 Prague, Czech Republic \\ e-mail: prachar@vzlu.cz,web page: http://www.vzlu.cz \\ Czech Aerospace Research Centre (VZLU) \\ Beranovych 130, 19905 Prague, Czech Republic \\ e-mail: smid@vzlu.cz,web page: http://www.vzlu.cz \\ ${ }^{\S} \mathrm{NLR}$ - Netherlands Aerospace Centre \\ P.O. Box 90502, 1006 BM Amsterdam, The Netherlands \\ e-mail: jan.middel@nlr.nl,web page: http://www.nlr.nl
}

Key words: CFD, radome, drag reduction, emissions

\begin{abstract}
This paper shows the drag and emission reduction potential of integrated, flush communication antennas at the surface of an airliner. The CFD simulations of the aircraft model representing a modern airliner with radome in different locations on its upper part of the fuselage have been done. The results have been compared with the baseline configuration of the aircraft without radome. The aerodynamic equivalent weight penalty and additional fuel needed due to the drag of the radome and its weight itself have been calculated by two approaches. The obtained drag reduction potential has been used for the estimation of the $\mathrm{CO}_{2}$ and $\mathrm{NO}_{\mathrm{x}}$ emissions reduction by using integrated antenna.
\end{abstract}

\section{INTRODUCTION}

The protection of the environment and reduction of the environmental footprint of air transport is very demanding Among others, growing air traffic also significantly contributes to the emissions contributing to climate change and local air quality issues around airports. Very ambitious goals have been set by politicians; a reduction of $2 \%$ in fuel consumption (and thus CO2 emissions) for aviation by 2021 and then by 2\% per year until 2050 [1]. Many operational improvements and new technologies have to be adopted to achieve this ambitious goal. One new technology is to replace the protruding communication antennas by integrated one with the aircraft outer skin can be used to contribute to the defined requirements $[2,3]$. The structurally integrated antennas cause less additional drag, noise and turbulence in comparison with classical protruding antennas. These antennas also reduce the maintenance costs and possible operational delays by avoiding collisions of protruding parts with airport cargo 
vehicles. The European project ACASIAS [4] addresses, among others, the topic of integrated antennas and their effect on aerodynamic performances and environment. The project researches VHF antennas that can be integrated into the fuselage panels or winglet's surface [3], e.g. This paper is focusing on the evaluation of the aerodynamic effect of the integrated antenna with the aircraft fuselage and its impact on the weight and fuel savings by eliminating the need for a radome. The possible emissions reductions by integrated antenna have also been evaluated.

\section{METHODS}

\subsection{Aircraft model}

The NASA Common Research Model (CRM) [5] designed by Boeing and among other purposes has been used during the Drag Prediction Workshops (DPW) [6] to obtain the experimental data for CFD code verification. It is based on a transonic transport configuration designed to fly at a cruise Mach number, $\mathrm{M}=0.85$ at design lift coefficient $\mathrm{CL}=0.5$. Several configurations of the CRM can be used. The horizontal tail and nacelle/pylon can be integrated into the baseline configuration which contains the wing and body, only. The CRM model used for this study is depicted in Fig. 1. The considered baseline configuration corresponded to the wing, body and horizontal tail, without radome.
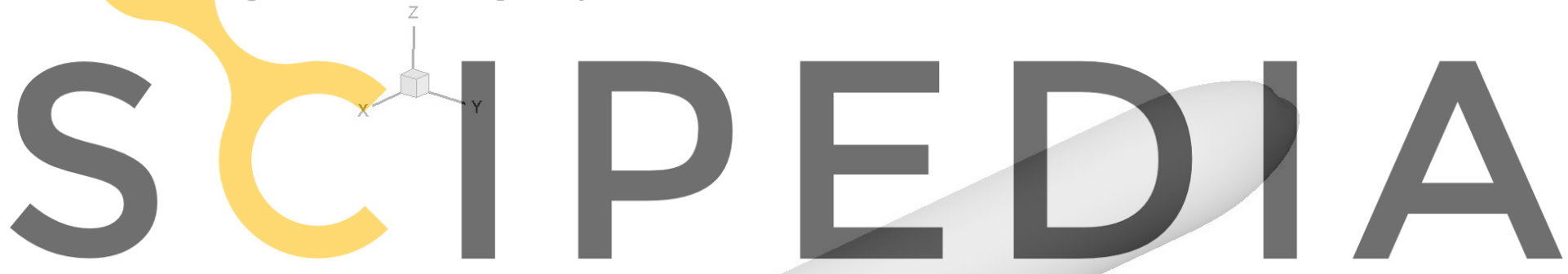

Register for free at https//www.scipedia.com to download the version without the watermark

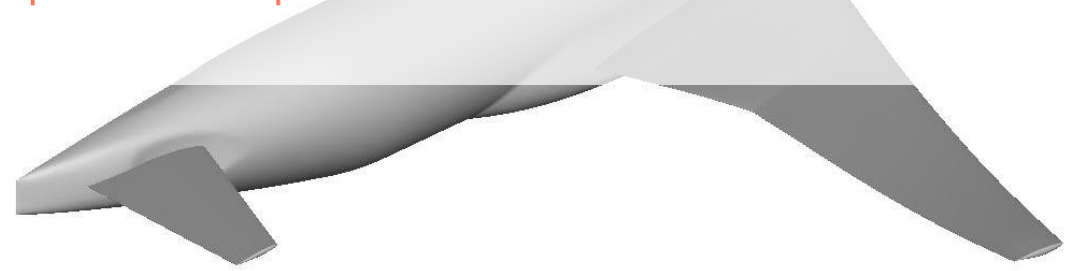

Figure 1: Baseline configuration of Common Research Model

The radome was placed in four locations along the fuselage, two in front of the wing (marked G_0 and $G_{-} 1$ ), one over the wing (marked $G_{-} 3$ ) and one in the rear (marked $\mathrm{G}_{-} 2$, see Fig. 2). The positions of the radome have been determined according to the $\overline{\mathrm{Cp}}$ distribution (local velocity) along a fuselage of the baseline configuration. The geometry of the radome corresponds to the low-profile Gogo $2 \mathrm{Ku}$ antenna [7]. 


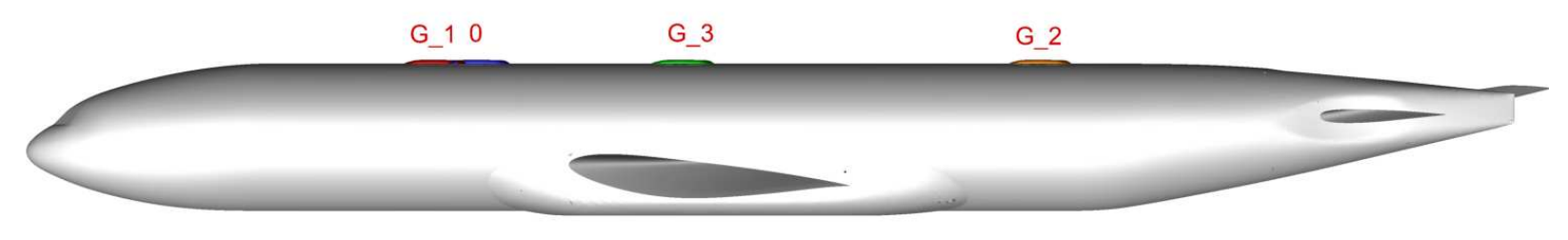

Figure 2: Considered positions of the radome along the fuselage

\subsection{Calculation of the Aerodynamic Equivalent Weight Penalty and additional fuel}

The weight penalty due to the presence of the radome were calculated by two approaches. The first one was introduced and applied by the radome's producer [7] and is called Aerodynamic Equivalent Drag Penalty (AEDP). It assumes that the value of the lift over drag ratio is constant during the cruise part of the flight.

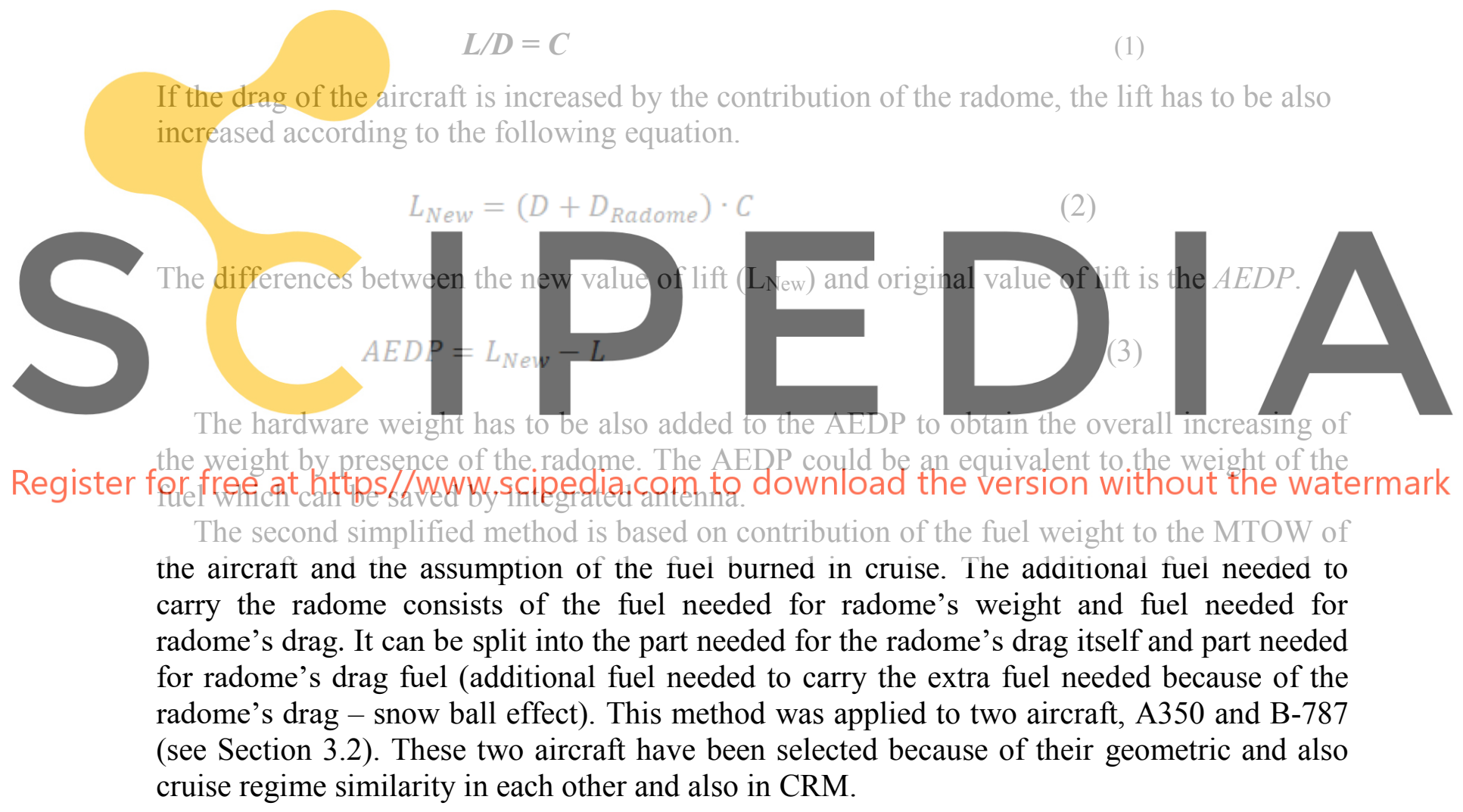

\subsection{Mesh generation, flow solver and flow conditions}

The computational grids were generated by Pointwise software [8]. They are unstructured grids with rectangular elements on the model surfaces, prismatic layer and tetrahedron elements in the volume. The height of the first layer was set to fulfill the demand of the turbulence model on the value of the $\mathrm{y}+$ function. The grid topology was the same for all considered configurations. The differences were only in close vicinity of the radome.

The Reynolds average Navier-Stokes (RANS) equations are solved in in-house CFD 
program. It is a finite volume Navier-Stokes solver for unstructured meshes. The k- $\omega$ EARSM [9] turbulence model was used for this study. All simulations were run as a fully turbulent flow. A farfield boundary condition was used on the outer boundary of the computational domain. This condition is specified by Mach number, flow direction, static pressure and static temperature. The aircraft was treated as no-slip viscous boundary. Symmetry boundary condition was used at the symmetry plane of the half model.

Freestream Mach number 0.85 and the Reynolds number $30 \cdot 10^{6}$ based on mean aerodynamic chord were used. Angle of attack was varied during the simulations to obtain constant lift coefficient 0.5 .

\section{RESULTS}

\subsection{Effect of the location of the radome on the drag}

The drag of the aircraft with different locations of the radome was evaluated for the constant lift coefficient $(C L=0.5)$. It means that the angles of attack were slightly different for different radome locations to obtain the same aerodynamic loading. The drag increment, caused by the presence of the radome in particular locations, is depicted in Fig. 3. The drag is increased from $0.07 \%$ up to $0.75 \%$ related to the baseline configuration. The best positions of the radome are in the front and in rear part of the fuselage while the overwing position (marked as G_3 in figure 2) is the worst. The higher drag in the overwing position is due to

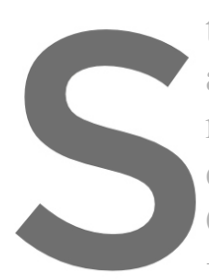
the locally accelerated flow caused by the wing(lift). This shows from the Cp along the fuselage depicte nose of the fuselage anc coordinate). The suitable Cp distribution with lower local flow velocity
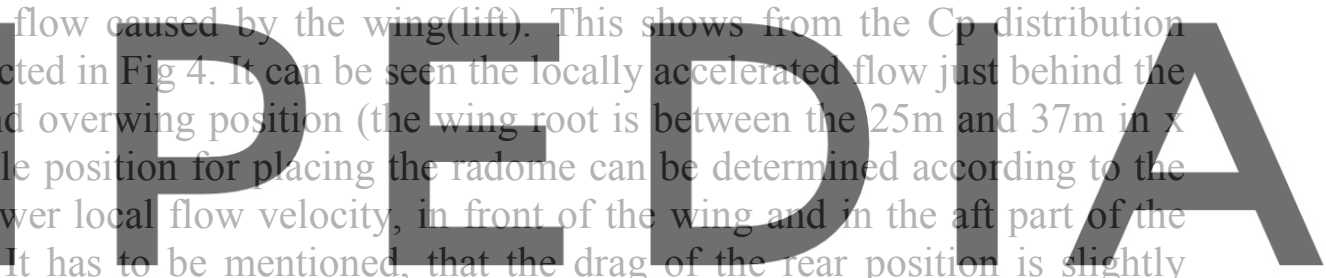

biased due to the missing the vertical tail plane.

Register for free at https//wwwkscipedia.com to download the version without the watermark

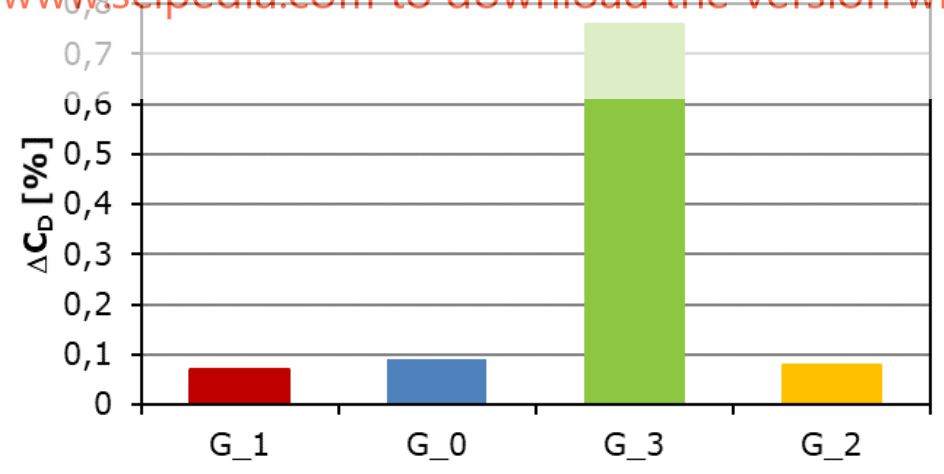

Figure 3: Drag increment by presence of the radome in different locations 


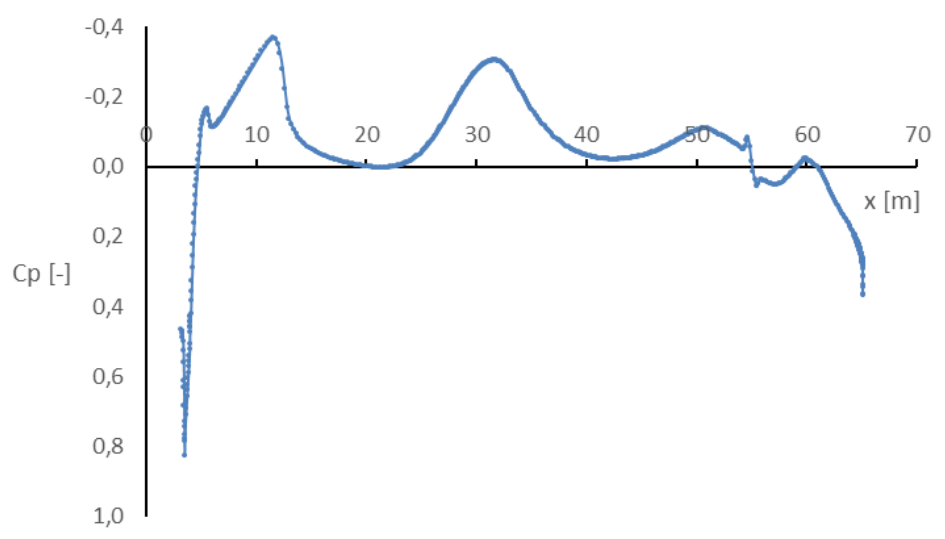

Figure 4: Cp distribution along the fuselage of the baseline configuration

The values of the drag force corresponding to the particular locations of the radome were used for further calculations of the aerodynamic equivalent drag penalty and the additional fuel needed.

\subsection{Weight penalty due to the presence of radome}

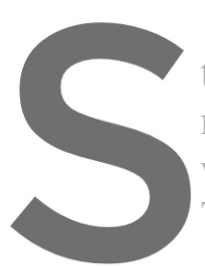

\section{The aerodynamic}

to calculate the AEDP.

method takes into acdo

weight of the radome $\mathrm{h}$

The results are depicted

$5(1 e f)$

The second method of caletlation of the
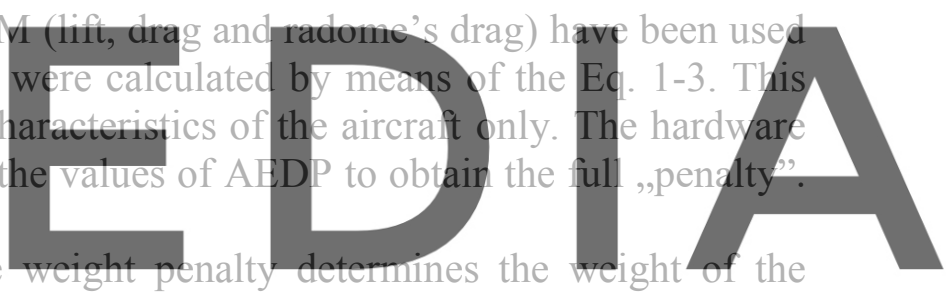

additional fuel needed to carry the radome itself (hardware weight and radome's drag) and

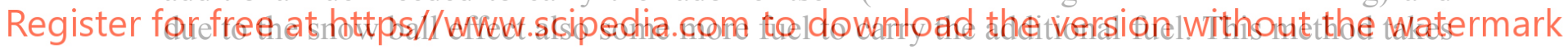

more into account the flight profile and the ratios between maximum take-off weight

(MTOW), fuel weight, burned fuel during the cruise, etc. For the purpose of this study two aircraft and their parameters (MTOW, fuel weight, etc.) have been used, A350 and B-787. The value of L/D for cruise condition was considered the same for both aircraft. It could be reason for the differences in calculated weight penalty between these aircraft (see Fig. 5 right). Some other differences are caused by the characteristics of the aircraft themselves (A350 is slightly larger in comparison with CRM whilst B-787 is slightly smaller). The results of this method are also depicted in Fig. 5 (right). It could be seen that both methods gave similar results and penalize the same configuration.

The results of both methods are rather informative. The precise aerodynamic, geometrical and weight characteristics of the real considered aircraft need to be taken into account to obtain correct absolute values of the weight penalty. On the other hand, the trend of the effect of the radome in particular positions can be used from this procedure. 

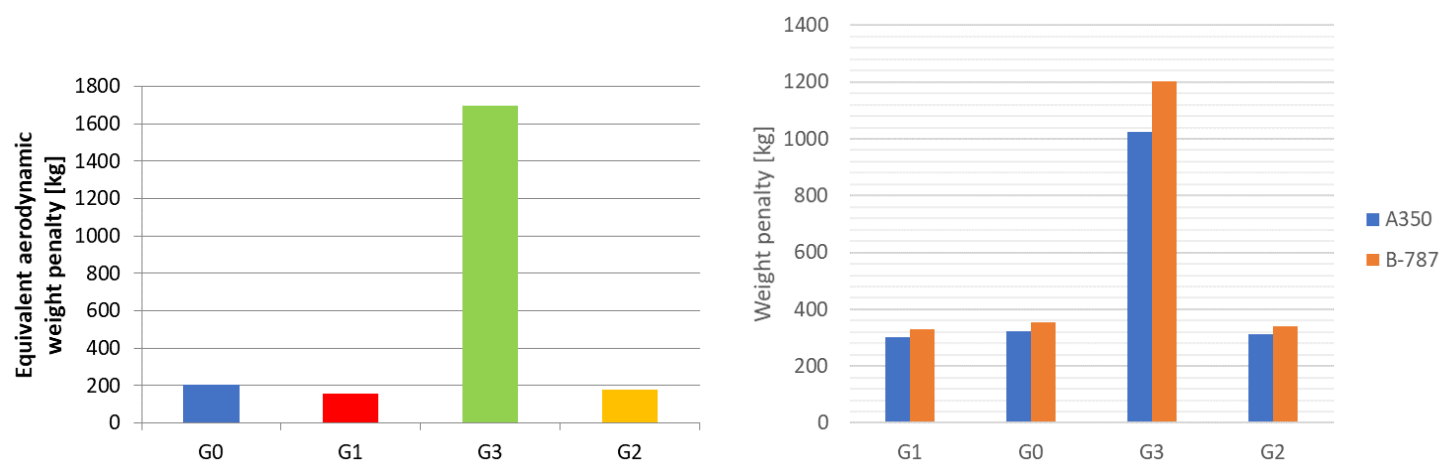

Figure 5: Aerodynamic Equivalent Drag Penalty (left) and weight penalty for two aircraft (right)

\subsection{Possible reduction of the $\mathrm{CO}_{2}$ and $\mathrm{NO}_{x}$ emissions by integrated antennas}

The $\mathrm{CO}_{2}$ and $\mathrm{NO}_{\mathrm{x}}$ emissions can be calculated or obtained by several methods. One of these methods is the calculation of the emissions from the chemical reactions inside the combustion chamber using its efficiency and selected regime [10]. Another method is based on the data provided by the engines' manufacturers. International Civil Aviation Organization (ICAO) organization manages the aircraft engine emission databank database [11], where the fuel consumptions and emissions of particular engines are defined and measured in reference static conditions for four thrust settings typical for take-off climb-out, approach and taxi. For low altitude and low speeds, as typical for airports, this database ean be directly applied to the effect of integrated antennas with the aircraft's surface in terms of $\mathrm{CO}_{2}$ and $\mathrm{NO}$, emissions, the engine type of the aircraft is known. The example-of the estimation of the emissions in dependence on the fuel consumption for an ideal engine Similar graphs of production of $\mathrm{CO}_{2}$ and $\mathrm{NO}_{\mathbf{x}}$ emission in dependenee on the thr can be also drawn.

Register for free at https//Www.scipedia.com to download the version without the watermark

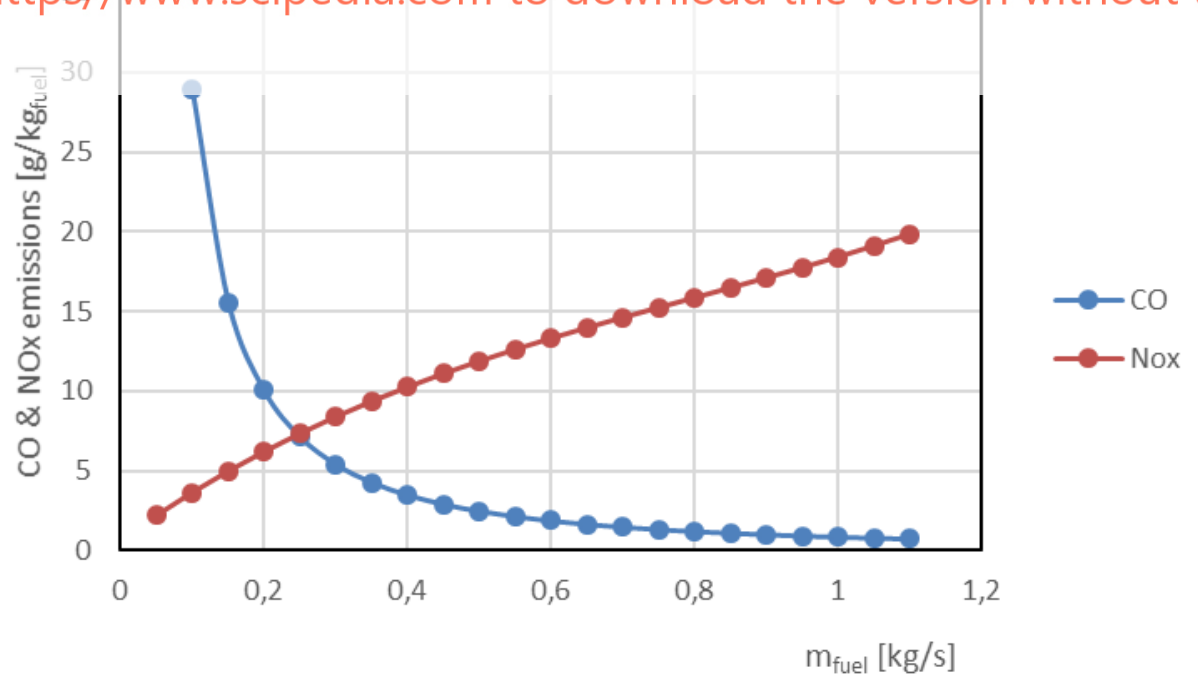

Figure 6: $\mathrm{CO}_{2}$ and $\mathrm{NO}_{\mathrm{x}}$ emissions for ICAO Aircraft Engine Emissions Databank engine [11] 
The $\mathrm{NO}_{\mathrm{x}}$ emissions production of the A-350-900 aircraft during typical flight $(7000 \mathrm{~km}$ trip) was calculated. The values of the drag increment have been taken over from the simulations of CRM. These correspond to the worst case (overwing location, G3) and the rear location $(\mathrm{G} 2)$ of the radome. The results of the estimation of the $\mathrm{NO}_{\mathrm{x}}$ production together with the estimation of the fuel consumption are in the following table. It is possible see the savings of the amount of the fuel burned $(\sim 0.6 \%)$ and NOx emissions produced $(\sim 2 \%)$ during the flight corresponded to the overwing radome's location and negligible savings for the rear radome's location.

Table 1: Results of the estimation of the emission production for typical flight w/o radome

\begin{tabular}{|l|r|r|r|l|}
\multicolumn{2}{l}{ no radome } & \multicolumn{1}{l}{ Radome G3 Radome G2 } \\
\hline fuelburn & 51760.24 & 52076.38 & 51764 & {$[\mathrm{~kg}]$} \\
\hline fuelestimate (incl. reserves) & 53871.93 & 54388.09 & 53878.39 & {$[\mathrm{~kg}]$} \\
\hline time & 530.52 & 530.65 & 530.52 & {$[\mathrm{~min}]$} \\
\hline travel distance & 7004.09 & 7004.09 & 7004.09 & {$[\mathrm{~km}]$} \\
\hline takeoff mass & 238153.78 & 238540.30 & 238158.76 & {$[\mathrm{~kg}]$} \\
\hline NOx emissions & 1900.85 & 1941.63 & 1901.36 & {$[\mathrm{~kg}]$} \\
\hline
\end{tabular}

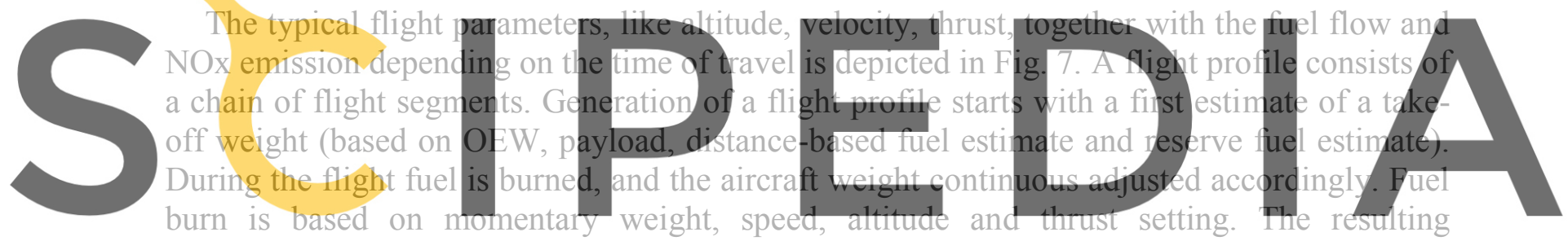
momentary (fuel) weight at touchdown is used to correct the initial calculated/estimated fuel

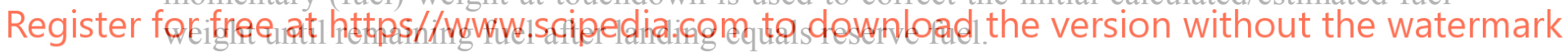

The production of the emissions is based on fuel flow, speed and altitude. The Boeing-2 fuel flow method (e.g. [12]) is used to calculate the NOx emissions along the flight profite. Boeing-2 fuel flow method is a well-accepted, standard method of estimating NOx. Integration along the flight profile yields NOx emissions and fuel burn. The drag difference between the two aircraft configurations is relatively small. The resulting flight profiles and NOx emissions are then hard to distinguish in the graphs depicted in Fig. 7. Visually they coincide.

The $\mathrm{CO}_{2}$ emissions are proportional to the fuel burn (see [13]). With reference to Table 1 it can be expected that the reduction of $\mathrm{CO}_{2}$ emissions will be about $0.6 \%$ compared to a radome installed at the worse location G3 is being replaced by a conformal (flush integrated) $\mathrm{Ku}$-band antenna as developed in the ACASIAS project. This follows from the relative difference between fuel burn between the radome at location G3 and flush antenna. When the radome is installed at position $\mathrm{G} 2$, then the $\mathrm{CO}_{2}$ savings are negligible 

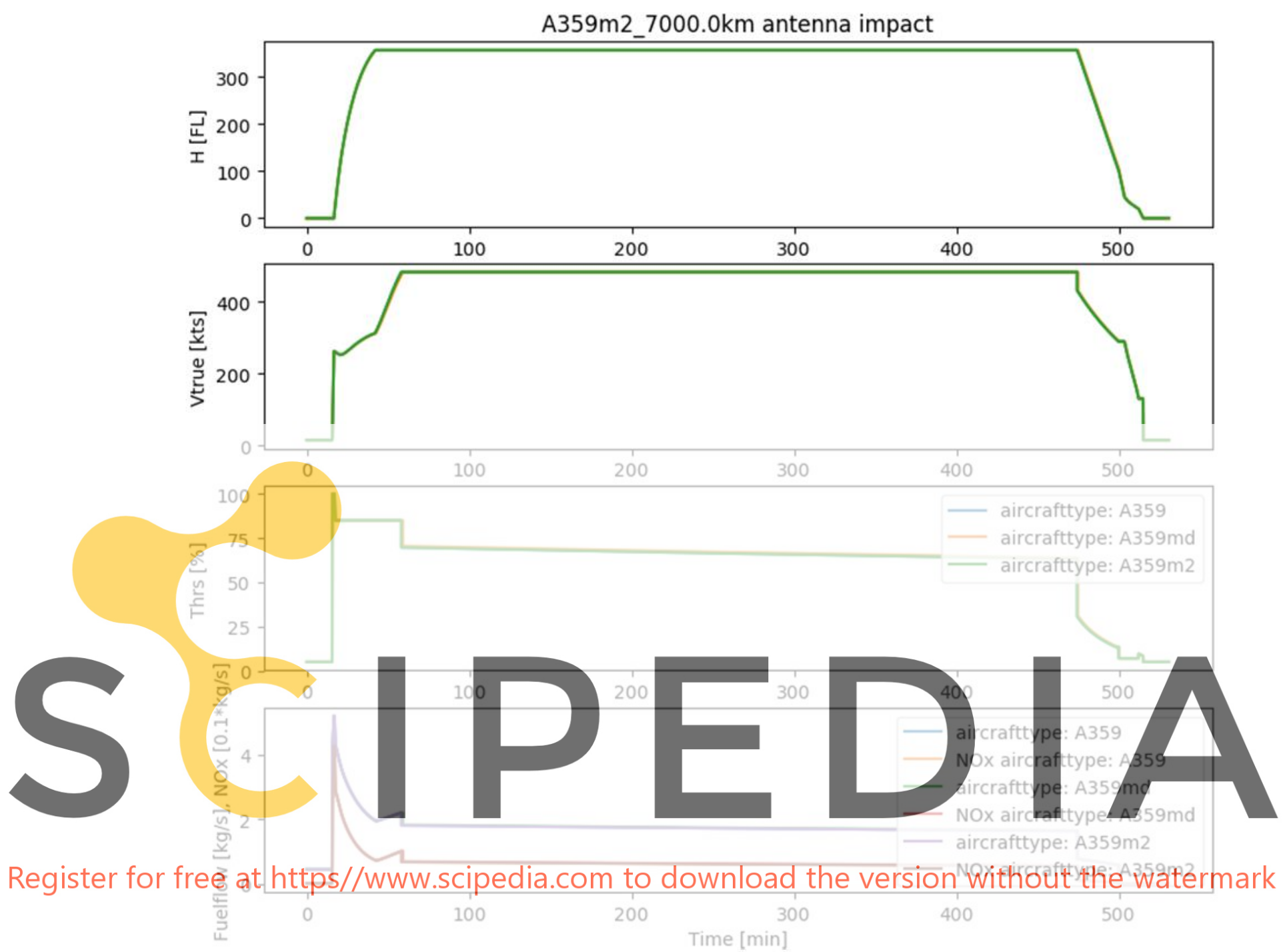

Figure 7: Fuel flow. NOx emissions and parameters of the typical flight of A-350-900

\section{CONCLUSIONS}

- The effect of the radome on the particular location along the fuselage of the airliner has been evaluated by CFD simulations. NASA Common Research Model has been used as a reference aircraft. The values of the radome's drag and aerodynamic characteristics of the aircraft were used to calculate the AEDP and additional fuel which is needed to carry the radome. The method used for calculation of the fuel needed to carry the radome takes into account the flight profile.

- The aerodynamic effect of the radome or protruding antennas can be expressed by the AEDP or by the weight of the additional fuel needed to carry the radome. It has been found that there can be benefit in hundreds of kilograms in case that the radome will be integrated with the aircraft's surface.

- Another advantage of the integrated antenna is the reduction of the vibration, Noise, 
maintenance costs and operational delays reducing risk to protrude parts by collisions with airport cargo cars.

- It has been found that it is possible to reduce the $\mathrm{NO}_{\mathrm{x}}$ emission of the typical flight up to $2 \%$ and $\mathrm{CO}_{2}$ emission by about $0.6 \%$ by integration of the radome into the fuselage in comparison with the baseline configuration and the worst radome's location. There is negligible saving of the fuel consumption and emissions reduction for the rear location of the radome. The main benefits of this configuration are savings of the additional weight (fuel needed to carry the radome itself) and the other reasons described above.

\section{ACKNOWLEDGMENTS}

All work described in this paper has received funding from the European Union's Horizon 2020 research and innovation programme under grant agreement No 723167. ACASIAS project.

This work was supported by The Ministry of Education. Youth and Sports of the Czech Republic from the Large Infrastructures for Research. Experimental Development and Innovations project IT4Innovations National Supercomputing Center LM2015070.

\section{REFERENCES}

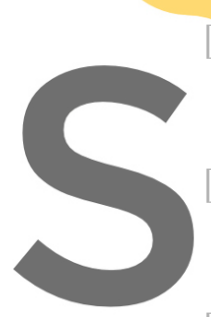

[1] P. Glowacki. M., Kawalec. S. Czyz, Aviation - Enviromental Threats, Simplified Methodology of $\mathrm{NO}_{\mathrm{x}}$ and $\mathrm{CO}_{2}$ emissions estimation, 5th CEAS Air \& Spade Conference
Challenges in European Aerospace, Delft, 2015
H. Schippers, J. Verpoorte, A. Hylzinga, C. Roloffen, and R. Baggen, Towards
structural integration of airborne Ku-band SatCom antenna, 7th European Conference on
Antennas and Propagation (EuCAP), 2013, pp. 2963-2967.

[3] P. Vrchota, S. Steeger, M. Martínez-Vázquez, M. Světlík, Z. Rezníček, "Aerodynamic and

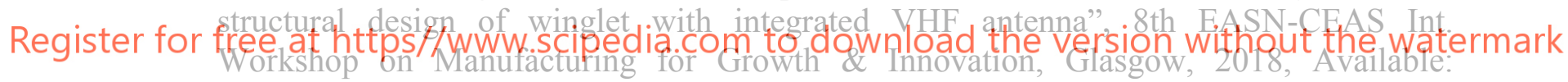
https://doi.org/10.1051/matecconf/201823300018

[4] ACASIAS project website: http://www.acasias-project.eu/

[5] Vassberg, J. C., DeHaan, M. A. Rivers, M. B. and Wahls, M. S., Development of a Common Research Model for Applied CFD Validation Studies, AIAA Paper 2008-6919. 2008.

[6] Drag Prediction Workshop website: http://aaac.larc.nasa.gov/tsab/cfdlarc/aiaadpw/Workshop5/

[7] GoGo website: https://www.gogoair.com/commercial/inflight-systems/2ku/

[8] Pointwise website: https://www.pointwise.com/index.html

[9] Wallin, S. and Johansson, A. V., \An Explicit Algebraic Reynolds Stress Model of Incompressible and Compressible Flows," Journal of Fluid Mechanics, Vol. 43, No. 9, 2000, pp. 89\{132, also AIAA Paper 89\{0269, Jan. 1989.

[10] V. Betak, J. Kubata, Numerical prediction of soot formation in combustion chamber for small jet engines, EFM15 - Experimental Fluid Mechanics 2015, Prague, 2015

[11] ICAO Aircraft Engine Emission Databank: https:// easa.europa.eu/documentlibrary/icao-aircraft-engine-emissions-databank 
[12] Schaefer, M., Bartosch, S., Overview on fuel flow correlation methods for the calculation of NOx, $\mathrm{CO} 2$ and $\mathrm{HC}$ emissions and their implementation into aircraft performance software, 2013

[13] Ashok, A., Dedoussi, I. C., Yim, . H. L., Balakrishnan, H., Barrett, S. R. H., Quantifying the air quality-CO2 tradeoff potential for airports, Atmospheric Environment 99, 2014, pp. 546-555
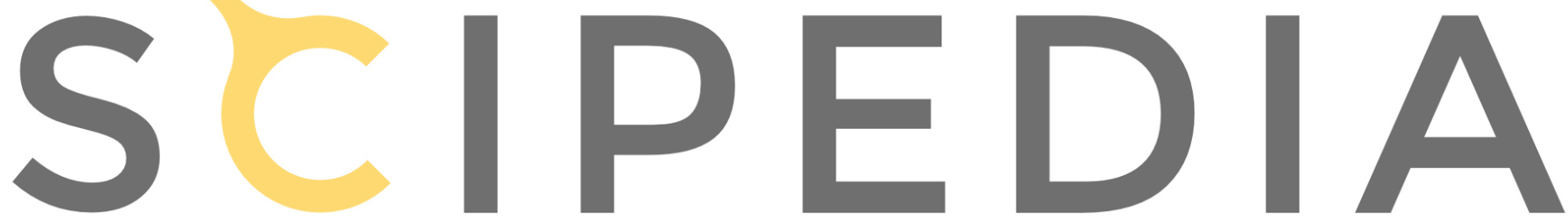

Register for free at https//www.scipedia.com to download the version without the watermark 